\title{
Seromarkers of collagen I and III metabolism in active Crohn's disease. Relation to disease activity and response to therapy
}

\author{
J Kjeldsen, O B Schaffalitzky de Muckadell, P Junker
}

\begin{abstract}
Crohn's disease is characterised by gradual development of intestinal fibrotic lesions containing large amounts of collagen type I, III, and V. Measurement of circulating connective tissue metabolites has emerged as a useful tool for assessment of fibroproliferative activity in various diseases. Serum concentrations of procollagen peptides, $\mathbf{N}$-terminal propeptide of type III procollagen (PIIINP), and C-terminal propeptide of type I procollagen (PICP), reflect the synthesis rate of the parent collagens, while the C-terminal telopeptide of type I collagen (ICTP) reflects its degradation. S-PIINP, S-PICP, and S-ICTP were measured by radioimmunoassays in 29 patients with active Crohn's disease. SICTP was significantly increased, median $6.2 \mu \mathrm{g} / 1$ (95\% CI 5.2 to $8.7 \mu \mathrm{g} / \mathbf{l})$ versus controls $2 \cdot 6 \mu \mathrm{g} / \mathbf{l}(2.5$ to $2.7 \mu \mathrm{g} / \mathbf{l})$ $(\mathbf{p}<0.0001)$, S-PICP reduced, $100 \mu \mathrm{g} / 1$ (80 to $110 \mu \mathrm{g} / \mathrm{l})$ versus $132 \mu \mathrm{g} / 1$ (124 to 141 $\mu g / l)(p=0 \cdot 001)$, and S-PIIIP did not differ from controls. Patients with sustained clinical remission during prednisolone therapy exhibited an increase in S-PICP $(p=0 \cdot 0052)$.S-PIIINP changed significantly $(p=0 \cdot 0002)$, however, exhibiting a biphasic pattern. SICTP decreased $(p=0.015)$ in treatment responders but remained above the upper normal limit even when clinical remission had been achieved. Nonresponders showed no significant changes in any of the marker molecules of collagen synthesis or degradation. Correlations were found between SPIIINP and S-PICP $(p<0.005)$ and SICTP $(p<0.02)$, and between S-ICTP and S-orosomucoid $(p<0.005)$ and S-C reactive protein $(p<0 \cdot 02)$. By contrast, there was no relation between the connective tissue metabolites and Harvey Bradshaw Index. These data provide evidence that collagen I degradation is increased not only in active Crohn's disease, but also in patients entering clinical remission. The concurrent normal/low-normal values of markers of collagen formation may reflect a changed local or systemic elimination of the propeptides.

(Gut 1995; 37: 805-810)
\end{abstract}

Keywords: collagen, procollagen, Crohn's disease, prednisolone.
The transmural inflammation in Crohn's disease is accompanied by deposition of fibrotic tissue containing excessive amounts of collagen type I, III, and V. ${ }^{1-3}$ The longstanding inflammation characteristic of Crohn's disease may induce prolonged repair processes causing irreversible changes in the tissue architecture and stricture formation. In recent years several studies have shown that synthesis as well as degradation of various types of collagen can be monitored in biological fluids. While the procollagen peptides ( $\mathrm{N}$-terminal propeptide of type III procollagen (PIINP) and C-terminal propeptide of type I procollagen (PICP)) reflect the synthesis rate of the parent collagens, ${ }^{4-6}$ the C-terminal telopeptide of type I collagen (ICTP) is derived from cross linked collagen I thereby providing an estimate of its degradation. ${ }^{7}$ In, for example, rheumatoid arthritis $^{589}$ and myelofibrosis ${ }^{1011}$ measurement of these circulating connective tissue metabolites in serum have emerged as promising tools in the assessment of disease activity and prognosis. The purpose of this investigation was to study the concentrations of collagen metabolites in the systemic circulation in patients with active Crohn's disease to assess their applicability as markers of disease activity and their response to short-term therapy with prednisolone.

\section{Methods}

\section{Study population}

Twenty nine patients with clinically active Crohn's disease - that is, Harvey Bradshaw Index ${ }^{12}(\mathrm{HBI}) \geqslant 6$ (range 6-15) - and biochemical signs of inflammation - that is, S-orosomucoid $\geqslant 1.6 \mu / 1$ (normal range $0.62-1.42 \mu / 1)$ - were eligible. In one patient lack of serum permitted analysis of S-PIIINP, S-PICP, and S-ICTP at baseline only. The remaining 28 patients were studied sequentially during a treatment protocol with prednisolone for active Crohn's disease approved by the local ethics committee. The diagnosis of Crohn's disease relied on established clinical, radiological, and endoscopic criteria. ${ }^{13}$ Table I gives details about the patients. Only two patients were receiving low dose prednisolone treatment upon inclusion in the protocol. Disease activity was graded according to $\mathrm{HBI}$ and clinical remission was defined as a $\mathrm{HBI} \leqslant 4$. Five patients had undergone surgery, median time from surgery was 40 months (range 4-137). None of the patients had a history of liver or kidney disease. Three 
TABLE I Study population. Demographics and clinical details

\begin{tabular}{ll}
\hline Patients (n) & 29 \\
Sex (male/female) & $13 / 16$ \\
Age (y), median (range) & $30(18-57)$ \\
Newly diagnosed disease & 14 \\
Relapsing disease & 15 \\
$\quad$ Disease duration from diagnosis, median & \\
$\quad$ (range) (y) & $2 \cdot 5(0 \cdot 5-14)$ \\
Disease localisation & 7 \\
$\quad$ Small bowel & 11 \\
Small bowel and colon & 11 \\
$\quad$ Colon & 5 \\
Prior surgery & $40(4-137)$ \\
$\quad$ Months since surgery, median (range) & 13 \\
Prior treatment with glucocorticoids & $1(1-6)$ \\
$\quad$ Treatment periods, median (range) & \\
Starting dose of glucocorticoid & 11 \\
$\quad$ Prednisolone 40 mg daily & 18 \\
Prednisolone 75 mg daily & \\
\hline
\end{tabular}

patients had temporary increases in serum alkaline phosphatase during active disease.

\section{Treatment protocol}

The starting dose of prednisolone was $40 \mathrm{mg}$ or $75 \mathrm{mg}$ daily depending on disease activity and previous response to treatment as judged by the physician in charge of the patient. After inclusion into the study the patients were seen at weekly visits where the HBI was calculated. Patients who improved were given a dose reduction schedule: $75 \mathrm{mg}, 50 \mathrm{mg}, 40 \mathrm{mg}, 30$ $\mathrm{mg}, 20 \mathrm{mg}, 15 \mathrm{mg}, 10 \mathrm{mg}, 5 \mathrm{mg}$, and $0 \mathrm{mg}$. The patients received each dose for at least one week. Patients who had no or only temporary clinical improvement were withdrawn from the study if the treatment duration exceeded two weeks at doses $\geqslant 40 \mathrm{mg}$ prednisolone or four weeks at doses $\leqslant 30 \mathrm{mg}$ prednisolone on each dose step. Thus, treatment duration was variable and depended on clinical response. At inclusion seven patients received concomitant treatment with sulphasalazine or mesalazine (five patients with coeliac disease and two patients with small bowel disease only). Nine additional patients with colonic or ileocolonic disease started maintenance treatment with either sulphasalazine or mesalazine upon entering the study or within the first weeks of treatment with prednisolone.

\section{Measurement of connective tissue metabolites}

Samples were drawn in the morning, were centrifuged at $800 \mathrm{~g}$ for 10 minutes, and subsequently stored at $-80^{\circ} \mathrm{C}$ until analysis. Serum was obtained at entry, after four weeks, and at the end of treatment or withdrawal from the treatment protocol. S-ICTP, S-PIIINP, and SPICP were measured by means of radioimmunoassays (RIAs) manufactured by Farmos Diagnostica, Oulunsola, Finland. All samples were done in duplicate. Normal reference intervals were calculated by analysis of serum samples from healthy Danish blood donors, aged 20-70 years, and expressed as mean (2 SD). Measurement of S-PIINN was carried out according to Risteli et al. ${ }^{14}$ The intra and interassay coefficient of variation were 5.2 and $10 \%$, respectively, and the normal range was $1 \cdot 1-5.5 \mu \mathrm{g} / \mathrm{l}$, mean $3.4 \mu \mathrm{g} / 1$ (70 males and 70 females). PICP was assessed by means of another equilibrium type RIA based on the human C-terminal propeptide of procollagen $\mathrm{I}^{15}{ }^{16}$ Intra and interassay coefficient of variation were 3.2 and $7 \cdot 0 \%$. The normal range in 161 healthy blood donors ( 97 males and 64 females) was $46-234 \mu \mathrm{g} / \mathrm{l}$, mean $140 \mu \mathrm{g} / \mathrm{l}$. ICTP is the cross linked C-terminal telopeptide of type I collagen. It was measured by means of a recently developed assay system using human antigen as tracer. ${ }^{7}$ Intra and interassay coefficient of variation were 5.2 and $12 \%$ and the normal range in 139 healthy blood donors (74 males and 65 females) was $0.9-4.7 \mu \mathrm{g} / \mathrm{l}$, mean, $2.8 \mu \mathrm{g} / 1$. There were no differences in S-ICTP, S-PICP, or S-PIIINP between men and women in healthy controls.

\section{Statistical analysis}

The data were tested for normal distribution by performing normal probability plot of $S$ PICP, S-PIINN, and S-ICTP and by calculation of the Shapiro-Wilks and the Lilliefors modification of the Kolmogorov-Smirnov test. These tests showed that the parameters did not exhibit Gaussian distribution, hence nonparametric analysis was applied throughout. Median values and $95 \%$ confidence limits were calculated for S-PICP, S-PIINP, and SICTP. Median values were compared with values for healthy controls with a MannWhitney test, which was also used for comparison between patients who had or had not received prednisolone previously. Serum concentrations of connective tissue metabolites in relation to disease localisation were compared by Kruskal-Wallis one way analysis of variance.

Patients were grouped according to their response to treatment, those entering sustained clinical remission - that is, $\mathrm{HBI} \leqslant 4$ for at least four weeks - and those with no response or only partial response. Friedman analysis of variance by ranks was used for comparison of results at start, at week 4 , and by treatment end. ${ }^{17}$ Paired comparisons of S-PIIINP, SPICP, S-ICTP in patients regarded as nonresponders were performed using Wilcoxon's matched pairs signed rank test. Correlations were calculated with Spearman's rank correlation test. $p$ Values $\leqslant 0.05$ were considered significant except where correction for multiple comparisons were made.

\section{Results}

\section{RESULTS OF TREATMENT PROTOCOI}

\section{Patients achieving clinical remission}

Twenty two patients achieved sustained clinical remission (after a median of four weeks) and 17 patients were followed up until reduction of the prednisolone dose to $0 \mathrm{mg}$ had been accomplished (after a median of eight weeks, range: 6-20). In five patients treatment with prednisolone was not reduced because of continuous increases in acute phase reactants. In these patients the last samples were drawn before cessation of treatment with prednisolone 
TABLE II S-PIINP, S-PICP, and S-ICTP at start (one patient had the first sample drawn after two weeks). Median values and $95 \%$ confidence intervals. Comparison with healthy controls

\begin{tabular}{llcc}
\hline & No & Patients & Healthy controls \\
\hline S-PIINP $(\mu \mathrm{g} / 1)$ & $28^{\star}$ & $2 \cdot 4(2 \cdot 2$ to $3 \cdot 2)$ & $3.4(2 \cdot 9$ to $3 \cdot 5), \mathrm{NS}$ \\
S-PICP $(\mu \mathrm{g} / 1)$ & 29 & $100(80$ to 110$)$ & $132(124$ to 141$), \mathrm{p}=0.001$ \\
S-ICTP $(\mu \mathrm{g} / 1)$ & 29 & $6 \cdot 2(5 \cdot 2$ to $8 \cdot 7)$ & $2 \cdot 6(2 \cdot 5$ to $2 \cdot 7), \mathrm{p}<0.0001$ \\
\hline
\end{tabular}

^Serum was not available for analysis of S-PIIINP in one patient.

(after a median of seven weeks at a median dose prednisolone of $30 \mathrm{mg}$ ). In the remaining patients, the median treatment duration was nine weeks (range: $8-14$ ) in patients receiving

Figure 1: Course of $S$ PIIINP in patients achieving sustained clinical remission $(n=22)$ (circles and solid lines) at inclusion, after four weeks (two patients had the four week sample drawn after two and three weeks, respectively), and by end of treatment and in patients who did not achieve clinical remission $(n=5)$ (boxes and dashed lines) at inclusion and at withdrawal. Horizontal dashed lines represent the reference range for healthy controls. Patients achieving remission exhibited a biphasic pattern with a significant fall after four weeks followed by increasing values from four weeks to the end $(p=0.0002)$.

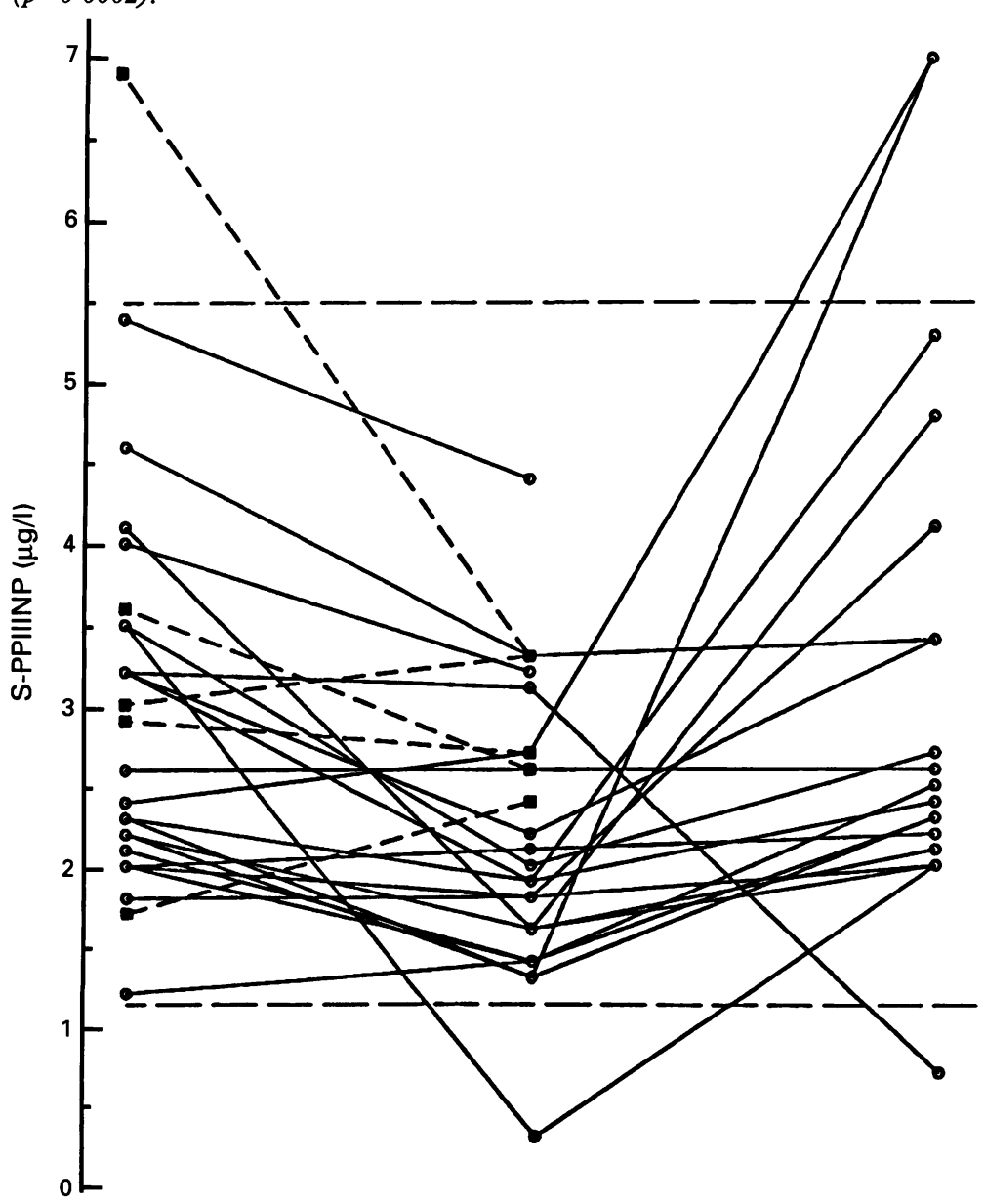

\section{$(n=29)$ \\ Baseline S-PIINP, S-PICP, and S-ICTP}

The median pretreatment values of S-ICTP were significantly increased compared with controls $(p<0.0001)$ (Table II). In 28 of 29 patients S-PICP was within the normal range

Six patients achieved no clinical remission or only partial response and were withdrawn from the treatment protocol as treatment failures after a median of seven weeks (range: 2-11).

\section{CONNECTIVE TISSUE METABOLITES} $75 \mathrm{mg}$ prednisolone and six weeks (range: $6-20$ ) in patients receiving $40 \mathrm{mg}$ prednisolone.

for healthy controls, but median S-PICP was significantly lower than in controls $(p=0.001)$ (Table II). By contrast, in 27 of 28 patients from whom serum was available, S-PIINP was within the reference interval and median S-PIIINP did not differ from the median value obtained in healthy controls (Table II). There was no difference in S-PIIINP, S-PICP, or SICTP between patients who had been treated with prednisolone in the past and patients treated for the first time (data not shown). Furthermore, there was no difference in S-ICTP, S-PICP, and S-PIINP between patients with different disease localisations, between relapsing or newly diagnosed disease, whether surgery had been performed or not, or whether patients received additional treatment with sulphasalazine or analogous compounds upon entry in the study (data not shown).

Correlations between HBI, biochemical indicators of inflammation, and connective tissue metabolites S-PIIINP correlated with S-PICP $(r=0.52$, $\mathrm{p}<0.005)$ and S-ICTP $(r=0.46, \mathrm{p}<0.02) . S$ ICTP correlated positively with S-orosomucoid $(r=0.54, \mathrm{p}<0.005)$ and $\mathrm{S}-\mathrm{C}$ reactive protein $(r=0.46, \mathrm{p}<0.02)$ and negatively with S-albumin $(r=-0.54, \mathrm{p}<0.005)$. Conversely, no correlation was present between procollagen peptides (S-PIIINP or S-PICP) and S-orosomucoid or S-C reactive protein, respectively. Furthermore, neither S-PIINP, S-PICP, nor S-ICTP correlated with the clinical activity as judged by the HBI.

Course of clinical disease activity, S-orosomucoid, $S$-PIIINP, S-PICP, and S-ICTP during treatment with prednisolone

In responders median HBI index decreased from 9 at start of treatment to 2 at end of treatment. Median serum concentration of orosomucoid fell from $2.22 \mu / 1$ to $1.49 \mu / 1$. Conversely, in non-responders median HBI was 11 upon inclusion and remained essentially unchanged throughout the study period. Median serum concentration of orosomucoid was $2.96 \mu /$ at inclusion and 2.22 at withdrawal.

The sequential course of S-PIIINP, S-PICP, and S-ICTP during treatment with prednisolone was studied in 28 patients in whom blood samples were available at different times during treatment. In patients achieving sustained clinical remission $(n=22)$ S-PIIINP showed a biphasic pattern within the normal range. A non-parametric analysis of variance for paired data of all patients with a complete set of measurements - that is, start, four weeks, and treatment end $(n=19)$ - showed a significant difference between the starting value, the value obtained after four weeks of treatment, and the value at treatment end $(p=0 \cdot 0002)$. Subsequent testing showed a decrease between start and four weeks, and subsequently an increase from week 4 to treatment end. In nonresponders S-PIIINP showed no change during the study period (Fig 1).

In responders S-PICP increased within the reference limits of healthy controls during the 

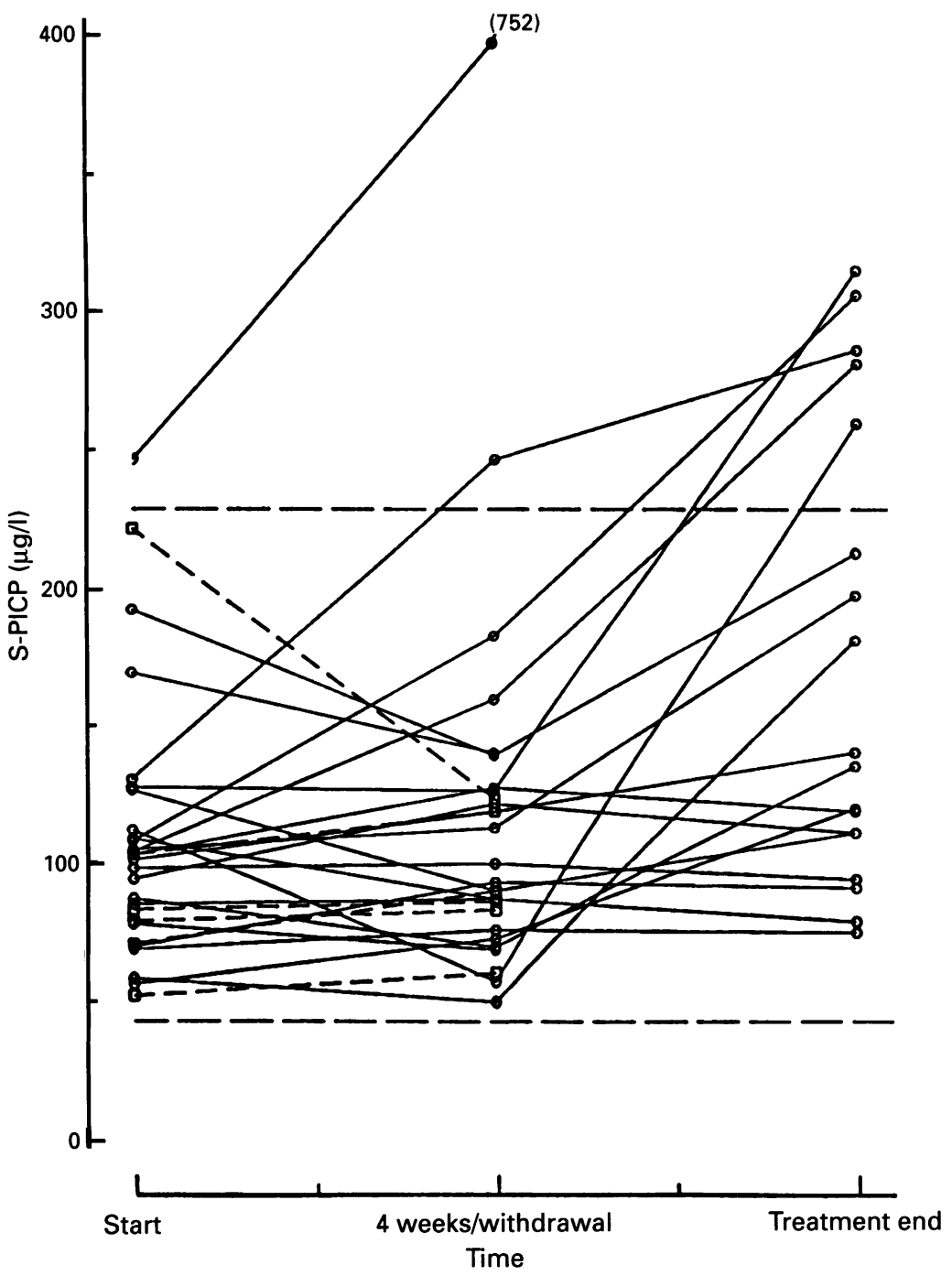

Figure 2: Course of S-PICP in patients achieving sustained clinical remission $(n=22)$ (circles and solid lines) at inclusion, after four weeks (two patients had the four week sample drawn after two and three weeks, respectively), and by end of treatment and in patients who did not achieve clinical remission $(n=6)$ (boxes and dashed lines) at inclusion and at withdrawal. Horizontal dashed lines represent the reference range for healthy controls. In responders, there was significant difference between the values obtained at start, after four weeks of treatment, and at treatment end $(p=0.0052)$. Pairwise analysis showed an increase between the starting values of S-PICP and those by treatment end.

whole study period $(\mathrm{p}=0.0052)$. S-PICP was unchanged in the subset of patients who were regarded as non-responders (Fig 2 ).

There was a statistically significant decrease in S-ICTP in patients achieving clinical remission $(p=0.0154)$. No change was seen in patients regarded as resistant to treatment (Fig 3).

\section{Discussion}

In this study we present evidence for the first time that the aberrant intestinal collagen metabolism in Crohn's disease is reflected in the systemic circulation. S-ICTP correlated significantly, although modestly, with acute phase reactants and S-albumin whereas no correlation was found between any of the connective tissue metabolites and the clinical index of activity, HBI.

Type I and III collagen are synthesised as larger proteins, procollagens. The $\mathrm{C}$ - and $\mathrm{N}$ terminal propeptides are cleaved off stoichiometrically once the procollagen molecule has been secreted into the extracellular space, thereby providing a basis for estimating the rate of collagen formation. Previous studies have shown that S-PICP and S-ICTP mainly reflect bone collagen metabolism because skeletal collagen exclusively consists of collagen I. ${ }^{4}$ 18-20 By contrast, PIIINP arises from soft connective tissues ${ }^{18}$ where collagen III frequently codistributes with collagen I. $^{20}$ The inflamed bowel segments in patients with Crohn's disease contain increased amounts of collagen I as well as III, and V. ${ }^{121}$ The cellular origin of the collagen in these patients is presently under debate. In vitro studies have shown that fibroblasts isolated from areas of strictured bowel produce more collagen III than fibroblasts from unstrictured intestine and control fibroblasts. ${ }^{3}$ However, intestinal smooth muscle cells are also a likely source of various collagens. ${ }^{122}$

There is now solid evidence that the serum concentrations of procollagen propeptides (SPIINP and S-PICP) are increased in a variety of fibroproliferative disorders, particularly in active stages of disease. ${ }^{4581011}$ By contrast, in this study we found low-normal and normal values of S-PICP and S-PIINP in active Crohn's disease with increasing concentrations of S-PICP and a biphasic course of S-PIIINP in patients responding to glucocorticoids. Glucocorticoids have previously been shown to be potent inhibitors of collagen formation. ${ }^{23}$ S-PIIINP and S-PICP are readily suppressed in healthy subjects and in patients with various skin diseases or rheumatoid arthritis undergoing short-term treatment with glucocorticoids. ${ }^{23-25}$ Several explanations can be offered for the present divergent findings. Firstly, propeptides may become degraded in the inflamed intestine by proteases produced by cells of the inflammatory infiltrate. This mechanism would be particularly pertinent in the most active phases of inflammation - that is, before treatment with prednisolone - where the lowest values were seen. Furthermore, as the radioimmunoassays applied in this study are designed to detect only the intact propeptides $^{14}$ even a high concentration of degradation products in the circulation would not be traced. In other settings, however, active fibroproliferation is characterised by preferential increments of authentic propeptides (rheumatoid arthritis and myelofibrosis). ${ }^{510}$ Secondly, the systemic metabolism of propeptides may be changed in active Crohn's disease. Thus, PIIINP and PICP are cleared by the liver endothelial cells by receptor specific mechanisms (the scavenger and mannose receptor, respectively). ${ }^{26-30}$ Although virtually nothing is known about what determines the expression and affinity of these receptor molecules it is intriguing to speculate that propeptides are cleared/taken up more efficiently from the portal blood in active disease compared with stable disease. ${ }^{31} 32$ The fact that collagen actually does accumulate provides strong evidence that intestinal collagen neoformation is enhanced. This is also supported by the findings of increased PIIINP concentrations in jejunal fluid in patients with Crohn's disease. ${ }^{33}$ Finally, in vitro studies have shown, that in contrast to fibroblasts, collagen synthesis is 


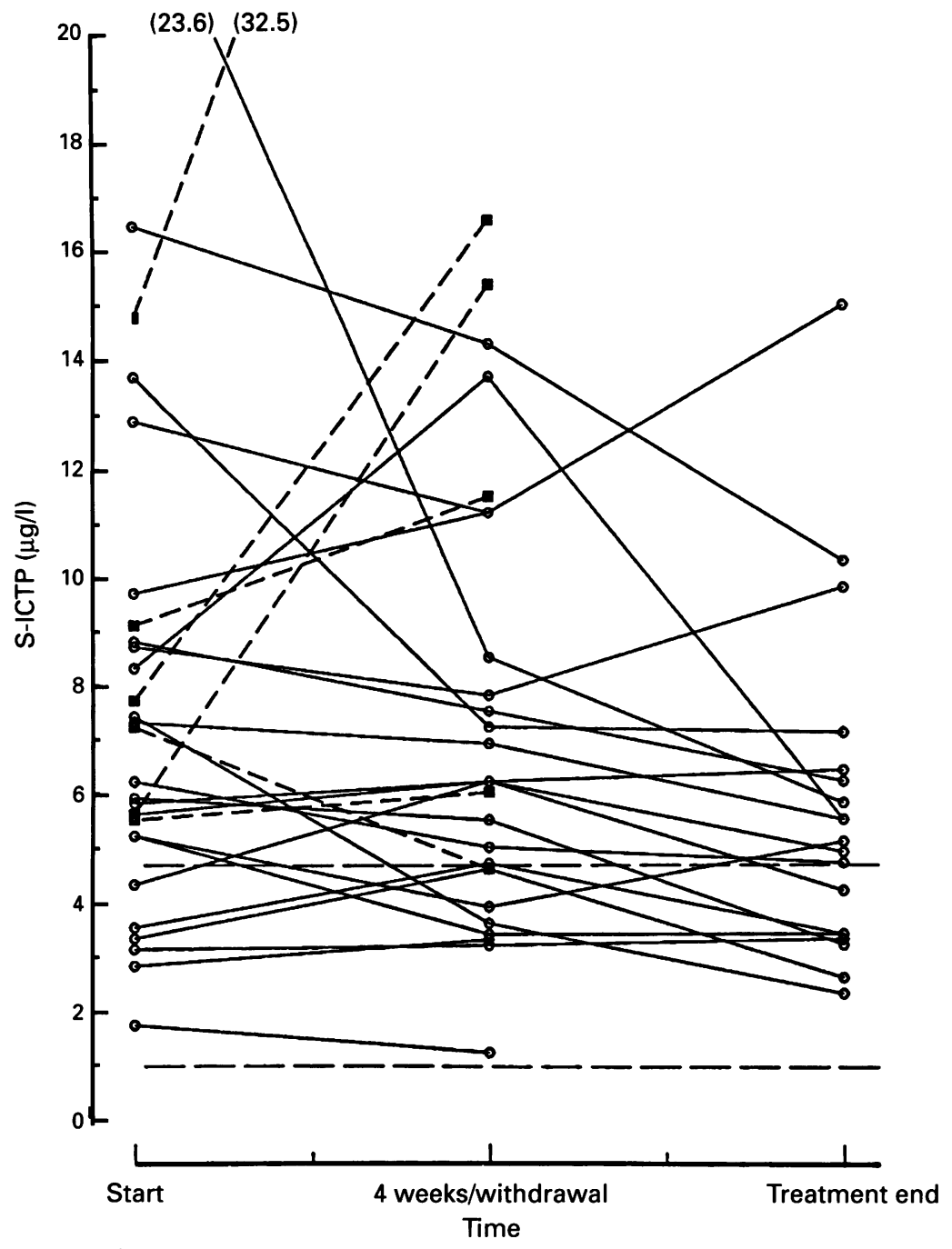

Figure 3: Course of S-ICTP in patients achieving sustained clinical remission $(n=22)$ (circles and solid lines) at inclusion, after four weeks (two patients had the four week sample drawn after two and three weeks, respectively), and by end of treatment and in patients who did not achieve clinical remission $(n=6)$ (boxes and dashed lines) at inclusion and at withdrawal. Horizontal dashed lines represent the reference range for healthy controls. There was a significant fall in patients achieving remission $(p=0.015)$ but no change in patients who were regarded as non-responders.

increased by intestinal human intestinal smooth muscle cell exposed to glucocorticoids. ${ }^{22} 34$ Accordingly, the increase in both $S$ PICP and S-PIIINP and the fall in S-ICTP in responders could reflect a shift from a highly tissue destructive state towards a fibroproliferative phase of the inflammatory process. Thus, the unanticipated rise of procollagen peptides in responders would seem to be a predictor of a favourable response to treatment in individual patients, whether because of a reduced local degradation or a change in receptor function by the liver endothelial cells.

The most prominent finding of our study was the constantly increased S-ICTP suggesting increased collagen I degradation. ICTP is a metabolically stable collagen fragment, which is cleared by the kidneys. ${ }^{411}$ It was originally introduced as a marker of bone degradation. Our findings are the first to show that S-ICTP is increased in a group of patients without overt signs of changed bone metabolism. Previous studies have shown, however, decreased bone density and total body calcium in a subgroup of patients with Crohn's disease and osteoporosis in up to $30 \%$ of patients with inflammatory bowel disease. ${ }^{35-38}$ Two sources of
ICTP should therefore be considered in this setting, namely, skeletal tissue and the intestinal fibrotic lesions. Even if collagen I synthesis can be suppressed after few days of glucocorticoid treatment, corticosteroid induced osteopenia does not seem to be a plausible explanation for our findings because: (a) only two patients were taking low doses of prednisolone upon inclusion in the study; (b) the patients were comparatively young; and (c) a considerable number of patients had newly diagnosed disease and had not previously been treated with glucocorticoids. In addition, it should be noted that S-ICTP was equally increased in patients previously untreated with glucocorticoids and in those with newly diagnosed disease and that renal function was normal in all our patients as estimated by $S$ creatinine. Finally, the present S-ICTP concentrations clearly exceeded those reported in osteoporosis where both S-PICP and S-ICTP are increased. ${ }^{420}$ It is probable, therefore, that the increased serum concentration of collagen degradation products is largely attributable to the remodelling processes in the inflamed intestine. The most plausible explanation for our findings is, that despite clinical remission as shown by the HBI, Crohn's disease is a chronic inflammatory disease like rheumatoid arthritis with smouldering repair processes taking place in apparently quiescent stages of disease. This concept is further supported by the finding that there is a changed crosslinking pattern of collagen in intestinal strictures leading to increased degradability. ${ }^{39}$ Hence, also in the setting, S-ICTP may emerge as a marker of collagen I degradation.

The positive correlation between acute phase reactants and S-ICTP favours the notion that the production and release of these substances are driven by the inflammatory process in the gut. ${ }^{40}$ The lack of correlation between the clinical index of activity and the connective tissue metabolites may merely reflect that HBI relies heavily on subjective parameters, which may result from both ongoing inflammation and changes in bowel function caused by irreversible structural changes.

In conclusion, measurement of collagen metabolites in the systemic circulation may provide an additional basis for assessment of disease activity and response to treatment in Crohn's disease. In contrast with acute phase proteins produced in the liver circulating collagen metabolites imply a direct way of assessing the fibrotic aspect of inflammation in Crohn's disease.

The study was supported by the Institute of Clinical Research, Odense University, Denmark and the Danish Association against Rheumatism. Parts of these data have previously been published as abstracts in Gastroenterology 1994; 106: 712 and Gut 1994; 35 (suppl 4): A123.

1 Graham MF, Diegelmann RF, Elson CO, Lindblad WJ, Gotschalk N, Gay S, et al. Collagen content and types in Gotschalk the intestinal strictures of Crohn's disease. 2 Graham MF, Drucker EM, Diegelmann RF, Elson CO. Collagen synthesis by human intestinal smooth muscle Collagen synthesis by human intestinal smooth
cells in culture. Gastroenterology 1987; 92: 400-5.

3 Stallmach A, Schuppan D, Riese HH, Matthes H, Riecken Stallmach A, Schuppan D, Riese $\mathrm{HH}$, Matthes $\mathrm{H}$, Riecken
EO. Increased collagen type III synthesis by fibroblasts isolated from strictures of patients with Crohn's disease. Gastroenterology 1992; 102: 1920-9. 
4 Risteli L, Risteli J. Biochemical markers of bone metabolism. Ann Med 1993; 25: 385-93.

5 Hørslev-Petersen K, Bentsen KD, Junker P, Lorenzen I. Serum amino-terminal type III procollagen peptide in rheumatoid arthritis. Arthritis Rheum 1986; 29: 592-9.

6 Jensen LT, Henriksen JH, Olesen HP, Risteli J, Lorenzen I. Lymphatic clearance of synovial fluid in conscious pigs: the aminoterminal propeptide of type III procollagen. Eur 7 Clin Invest 1993; 23: 778-84

7 Risteli J, Elomaa I, Niemi S, Novamo A, Risteli L Radioimmunoassay for the pyridinoline cross-linked carboxy-terminal telopeptide of type I collagen: a new serum marker of bone collagen degradation. Clin Chem 1993; 39: 635-40.

8 Hørslev-Petersen K, Bentsen KD, Engström-Laurent A, Junker P, Halberg P, Lorenzen I. Serum amino terminal III procollagen peptide and serum hyaluronan in rheumatoid arthritis: relation to clinical and serological parameters of inflammation during 8 and 24 months' parameters of inflammation during 8 and 24 months Ann Rheum Dis 1988; 47: 116-26.

9 Hakala M, Risteli L, Manelius J, Nieminen P, Risteli J. Increased type I collagen degradation correlates with disease severity in rheumatoid arthritis. Ann Rheum Dis 1993; 52: 866-9.

10 Hasselbalch H, Junker P, Hørslev-Petersen K, Lisse I, Bentsen KD. Procollagen type III aminoterminal peptide in serum in idiopathic myelofibrosis and allied conditions: relation to disease activity and effect of chemotherapy. Am ₹ Hematol 1990; 33: 18-26.

11 Elomaa I, Virkkunen P, Risteli L, Risteli J. Serum concentration of the cross-linked carboxyterminal telopeptide of type I collagen (ICTP) is a useful prognostic indicator in multiple myeloma. Br $¥$ Cancer 1992; 66: 337-41.

12 Harvey RF, Bradshaw MJ. A simple index of Crohn's disease activity. Lancet 1980; i: 514.

13 Malchow H, Ewe K, Brandes JW, Goebell H, Ehms H, Sommer $\mathrm{H}$, et al. European Cooperative Crohn's Disease Study (ECCDS): results of drug treatment. Gastroenterology 1984; 86: 249-66.

14 Risteli J, Niemi S, Trivedi P, Mäentausta O, Mowat AP, Risteli L. Rapid equilibrium radioimmunoassay for the amino-terminal propeptide of human type III procollagen. Clin Chem 1988; 34: 715-8.

15 Melkko J, Niemi S, Risteli L, Risteli J. Radioimmunoassay of the carboxyterminal propeptide of human type I procollagen Clin Chem 1990; 36: 1328-32.

16 Gram J, Bollerslev J, Nielsen HK, Junker P. Increased serum concentrations of type I procollagen C-terminal propeptide and osteocalcin during a short course of calcitriol administration to adult male volunteers. Acta Endocrinol 1991; 125: 609-13.

17 Siegel S, Castellan NJJ. Nonparametric statistics for the behavioral sciences. 2nd ed. New York: McGraw-Hill International, 1988.

18 Jensen LT, Olesen HP, Risteli J, Lorenzen I. External thoracic duct-venous shunt in conscious pigs for long term studies of connective tissue metabolites in lymph. Lab Anima Sci 1990; 40: 620-4.

19 Eriksen EF, Charles P, Melsen F, Mosekilde L, Risteli L, Risteli J. Serum markers of type I collagen formation and degradation in metabolic bone disease: correlation with bone histomorphometry. F Bone Miner Res 1993; 8: 127-32.

20 Charles P, Mosekilde L, Risteli L, Risteli J, Eriksen EF. Assessment of bone remodelling using biochemical indicators of indicators of type 1 collagen synthesis and degradation: 4; 24: 81-94.

21 Matthes H, Herbst H, Schuppan D, Stallmach A, Milani S, Stein $\mathrm{H}$, et al. Cellular localization of procollagen gene transcripts in inflammatory bowel disease. Gastroenterology 1992; 102: 431-42.

22 Graham $M$, Willey A, Adams J, Diegelmann $R$. Corticosteroids increase procollagen gene expression and secretion by human intestinal smooth muscle (HISM) cells in vitro: implications for stricture formation in Crohn's disease and lye ingestion [Abstract] Gastroenterology 1994; 106: 691.

23 Oikarinen A, Autio P, Vuori J, Väänänen K, Risteli L Kiistala U, et al. Systemic glucocorticoid treatment decreases serum concentrations of carboxyterminal propeptide of type I procollagen and aminoterminal propeptide of type I procollagen and aminoterminal 126: $172-8$.

24 Autio P, Risteli J, Kiistala U, Risteli L, Karvonen J, Oikarinen A. Serum markers of collagen synthesis and degradation in skin diseases. Altered levels in diseases with systemic manifestation and during systemic gluco-
corticoid treatment. Acta Dermatol Res 1993; 285: 322-7.

25 Lems WF, Jacobs JW, van-den-Brink HR, van-Rijn HJ Bijlsma JW. Transient decrease in osteocalcin and markers of type 1 collagen turnover during high-dose corticosteroid pulse therapy in rheumatoid arthritis. $B$ Y Rheumatol 1993; 32: 787-9.

26 Smedsrød B, Pertoft H, Gustafson S, Laurent C. Scavenger functions of the liver endothelial cell. Biochem $\mathcal{F} 1990$ 266: 313-27.

27 Bensten KD, Henriksen JH, Boesby S, Hørslev-Petersen K, Lorenzen I. Hepatic and renal extraction of type III procollagen amino-terminal propeptide and hyaluronan in pig. $\mathcal{F}$ Hepatol 1989; 9: 177-83

28 Smedsrød B, Melkko J, Risteli L, Risteli J. Circulating Cterminal propeptide of type I procollagen is cleared mainly via the mannose receptor in liver endothelial cells. Biochem f 1990; 271: 345-50.

29 Bentsen KD, Henriksen JH, Bendtsen F, Horslev-Petersen $\mathrm{K}$, Lorenzen I. Splanchnic and renal extraction of circulating type III procollagen aminoterminal propeptide in
patients with normal liver function and in patients with patients with normal liver function and in patients

30 Melkko J, Hellevik T, Risteli L, Risteli J, Smedsrød B Clearance of $\mathrm{NH}_{2}$-terminal propeptides of types I and II procollagen is a physiological function of the scavenger receptor in liver endothelial cells. $\mathcal{F}$ Exp Med 1994; 179: 405-12.

31 Berg S, Brodin B, Hesselvik F, Laurent TC, Maller R. Elevated levels of plasma hyaluronan in septicaemia. Scand 7 Clin Lab Invest 1988; 48: 727-32.

32 Kushner I. The phenomenon of the acute phase response. Ann NY Acad Sci 1982; 389: 39-48.

33 Colombel JF, Hälloren R, Engström-Laurent A, Rambaud JC. Hyaluronic acid and type III procollagen peptide in jejunal perfusion fluid as markers of connective tissue turnover. Gastroenterology 1989; 96: 68-73.

34 Graham MF. Stricture formation. Pathophysiologic and therapeutics concepts. In: MacDermott RP, Stenson WF, eds. Current topics in gastroenterology. New York: Elsvier Science, 1992: 323-35.

35 Ryde SJS, Clements D, Evans WD, Motley R, Morgan WD, Evans C, et al. Total body calcium in patients with inflammatory bowel disease: a longitudinal study. Clin Sci 1991; 80: 319-24.

36 Motley RJ, Clements D, Evans WD, Crawley EO, Evans C, Rhodes J, et al. A four-year longitudinal study of bone loss in patients with inflammatory bowel disease. Bone Miner 1993; 23: 95-104.

37 Compston JE, Judd D, Crawley EO, Evans WD, Evans C, Church HA, et al. Osteoporosis in patients with inflammatory bowel disease. Gut 1987; 28: 410-5.

38 Ghosh S, Cowen S, Hannan WJ, Ferguson A. Low bone mineral density in Crohn's disease, but not in ulcerative colitis, at diagnosis. Gastroenterology 1994; 107: 1031-9.

39 Alexander AC, Irving $\mathrm{MH}$. Accumulation and pepsin solubility of collagens in the bowel of patients with Solubility of collagens in the bowel of patients with

40 Mazlam MZ, Hodgson HJF. Interrelations between interleukin-6, interleukin-1 $\beta$, plasma $C$-reactive protein values, and in vitro C-reactive protein generation in patients with inflammatory bowel disease. Gut 1994; 35: $77-83$. 